\title{
QUANDO AS LETRAS CLÁSSICAS ENCONTRAM AS TEORIAS DA HISTÓRIA: O PROAERA, PROGRAMA DE ESTUDOS EM REPRESENTAÇÕES DA ANTIGUIDADE
}

\author{
Henrique Cairus* \\ Recebido em: 27/03/2020 \\ Aprovado em: 16/04/2020 \\ WHEN CLASSICAL PHILOLOGY MEETS THE \\ THEORIES OF HISTORY: THE PROAERA, PROGRAM OF \\ STUDIES ON REPRESENTATIONS OF ANTIQUITY
}

\section{DA HISTÓRIA}

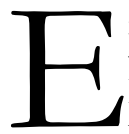

m 2006, numa conversa com a Professora (hoje Emérita) Nely Pessanha, na sala do Programa de Pós-Graduação em Letras da Clássicas da UFRJ, uniram-se no mesmo projeto três realidades que se impunham: a necessidade de criarmos núcleos de estudos que refletissem, ambientassem e estimulassem as duas linhas de pesquisa daquele Programa, a que estudava a Antiguidade e a que se dedicava ao Humanismo Português; a urgência de apontar a artificialidade da divisão feudo-departamentalista entre os então seis Programas de Pós-Graduação da Faculdade de Letras da UFRJ (hoje são sete!), e a premência de fortalecermos os estudos teóricos sem os quais, como pensamos, a erudição é, no máximo, um ornato. À Professora Nely, Professora Titular de Língua e Literatura Gregas, caberia a coordenação do grupo dedicado à Antiguidade, e ao Professor Titular de Língua e Literatura Latinas, a do núcleo que se voltaria para a pesquisa da Literatura Novilatina humanística. Este segundo grupo sequer foi consolidado, em virtude do precoce falecimento de seu líder.

Assim, nos primórdios do ano de 2007, nasce o Programa de Altos Estudos em Representações da Antiguidade, o Proaera. O adjetivo "alto" figurava no nome do grupo porque havia, então, a

\author{
* Professor Titular \\ de língua e literatura \\ grega, Universidade \\ Federal do Rio de \\ Janeiro. \\ hcairus@ufrj.br
}


veleidade de abrigar prioritariamente projetos de pós-doutorado. Esses projetos, contudo, só nos chegariam dez anos mais tarde, porque, pouco depois da fundação do Proaera, tanto a Professora Nely quanto eu retiramo-nos do Programa de Pós-Graduação em Letras Clássicas da UFRJ, onde não encontrávamos mais ambiente favorável ao trabalho que desenvolvemos.

Esse afastamento de seu berço funcionou, para o Proaera, como uma emancipação. Aos poucos, ao grupo associaram-se excelentes professores da UFES, da UFJF, da UNIRio e da UFRGS. Alguns anos mais tarde, esses professores fundaram seus próprios núcleos, entre os quais destaco o LIMES - Fronteiras Interdisciplinares da Antiguidade e suas Representações.

Mais recentemente, o Proaera teve a honra de acolher, como parte integrante sua, o núcleo Imagens da Antiguidade Clássica, da USP, coordenado pelo Professor Paulo Martins, Livre Docente de Língua e Literatura Latina naquela Universidade.

Hoje o Proaera conta com integrantes de diversas instituições, com sete membros efetivos (todos doutores), sete membros associados (todos doutores), oito doutorandos, duas mestrandas, dezesseis graduandos. Todos os discentes são orientandos de um dos membros efetivos, mas nem todos os orientandos dos membros efetivos integram o grupo, porque isso depende de a pesquisa desenvolvida ter relação com a identidade do Proaera.

\section{Da IDENTIDADE}

O que caracteriza o grupo, desde sua origem, é a percepção de que há um déficit teórico nos estudos de Letras Clássicas, que desenvolveram metodologias alicerçadas numa perspectiva positivista, e tais metodologias ainda não foram revistas nem no Brasil nem praticamente em nenhuma outra parte do mundo. Nossa reação a essa percepção foi uma aproximação quase espontânea com as teorias da História, porquanto são elas voltadas para a observação de um objeto inerente aos nossos interesses comuns, o passado. Com as teorias da História, vieram os historiadores. Esses foram convidados a frequentar o Proaera, e, depois, a integrá-lo. Foi um convívio profícuo, que nos pareceu ensejar uma relação de complementaridade.

O projeto, portanto, de unir erudição e teoria tem consistido na espinha dorsal do Proaera, mas não é o único elemento de sua identidade. A relação com as teorias da História levou o Proaera a uma decisão de abraçar a temporalidade como o fulcro de suas abordagens, por oposição à romântica atemporalidade em seus diversos formatos.

O núcleo do Proaera na UFRJ, assim, foi especializando-se nas tensões temporais, como o uso do passado, apropriações, emulações, imitações, adaptações, referências e modelos. O núcleo do Proaera na USP, o IAC, dedica-se à imagem da retórica, à retórica da imagem, à imagem poética e à poética imagética, estudando práticas textuais específicas, como, por exemplo, a écfrase. Finalmente, o núcleo filosófico do Proaera, dedicado à História da Filosofia com eixo firmado sobre a Antiguidade, é composto por alguns membros do Ousia, Laboratório de Filosofia Antiga da UFRJ, coordenado pelo Professor Fernando Santoro. O Ousia, o mais antigo parceiro do Proaera e seu "irmão" mais velho, foi, aos 
poucos e sempre parcialmente, adentrando o Proaera, e hoje uma parte sua também é uma parte nossa, e vice-versa.

\section{Do FUnCIONAMENTO}

Os membros do Proaera se reúnem semanalmente em cada um de seus núcleos exclusivamente para ler textos teóricos previamente selecionados no Encontro Anual. Uma vez por mês, contudo, essa reunião consiste em uma apresentação (em cinco minutos, no máximo) do que cada um dos membros do Proaera caminhou em sua pesquisa.

Anualmente, os três núcleos que atualmente formam o Proaera se reúnem alternadamente no Rio de Janeiro ou em São Paulo. Nesse Encontro Anual, todos os membros (docentes e discentes) enviam textos relativos à sua pesquisa em andamento, e, presencialmente, o autor de cada pesquisa ouve os demais membros sugerirem encaminhamentos, bibliografias, recortes etc. O autor da pesquisa não faz nenhuma apresentação, não há aplausos nem "comunicações". O autor apenas ouve, e eventualmente esclarece alguma questão, de acordo com alguma solicitação. Além das seções de discussão das pesquisas, o Encontro anual conta com duas conferências, geralmente de docentes convidados, externos ao Proaera.

O Proaera produz uma revista muito bem indexada e qualificada, com a periodicidade em dia, competentemente dirigida pelas Professoras Ana Thereza Basilio Vieira (Professora de Língua e Literatura Latina na UFRJ) e Beatriz de Paoli (Professora de Língua e Literatura Grega na UFRJ): a CODEX - Revista de Estudos Clássicos (https://revistas.ufrj.br/index. php/CODEX). Mantém também o informativo nacional InfoClassicas (www.pec.ufrj.br/ proaera/Lista.htm), com o selo da Sociedade Brasileira de Estudos Clássicos, e organiza diversos eventos avulsos, geralmente em parceria com outros grupos ou instituições.

As Teses (de todos os níveis) e Dissertações realizadas no seio do Proaera levam seu selo.

\section{DAS LINHAS DE PESQUISA}

O Proaera está estruturado em quatro Linhas de Pesquisa que abarcam seus interesses e, por conseguinte, compreendem sua produção. Os membros efetivos do Proaera participam de todas as Linhas de Pesquisa, contribuindo para seu desenvolvimento com orientações e publicações. Esse trânsito livre dos docentes pelas Linhas de Pesquisa é vital para a organicidade do Proaera. Cada uma dessas Linhas, no entanto, conta com um ou dois responsáveis por sua condução e sua integridade, mantendo-as dentro do espírito do grupo ao qual pertencem.

Na Linha de Pesquisa "História dos conceitos e teoria dos campos", são desenvolvidos projetos que se dedicam à investigação do percurso dos conceitos pelas vias do tempo, do espaço, das instituições, bem como de todo o aparato simbólico que os cerca. Essa Linha de Pesquisa também se debruça no estudo dos processos discursivos que 
formam, circunscrevem, definem e identificam um campo, entendido qual a proposição de Bourdieu. Responde pela direção dessa Linha de Pesquisa o autor deste texto em parceria com o Professor Fernando Santoro (UFRJ).

A Linha de Pesquisa "Imagens da Antiguidade clássica", dirigida pelo Professor Paulo Martins (USP), reúne projetos que trabalham com práticas discursivas que lidam com a visualidade e as estratégias de geração de imagens mentais a partir de um instrumental respaldado e codificado em espaços e tempos diversos da Antiguidade Ocidental.

As pesquisas voltadas para o estudo da presença, em textos, de projetos de civilização construídos a partir da tensão, pensada e constituída a partir de modelos da Antiguidade, entre identidade e alteridade, são abrigadas pela Linha "Projetos Civilizatórios", coordenada pela Professora Tatiana Ribeiro (UFRJ). Essa linha de pesquisa se ocupa também da investigação do lugar simbólico da Antiguidade nos processos civilizadores geridos pela Europa ou nela inspirados, como modelo ou contra-modelo.

A Linha de Pesquisa "Tradução, adaptação e apropriação" é dirigida pela Professoras Ana Thereza Basilio Vieira (UFRJ) e Beatriz de Paoli (UFRJ), e congrega projetos que se dedicam ao estudo acerca da tradução, da adaptação e da apropriação no que tange aos comprometimentos dessas práticas. Assim, busca essa Linha de Pesquisa perceber e, por vezes mapear, as relações dialéticas de tais práticas com questões epocais e espaciais, mediadas pelo imaginário, pela ideologia, pela teoria e por outros filtros oriundos da cosmovisão, do engajamento, da axiologia e do estar no mundo. A Linha ainda se ocupa de outras práticas como a imitatio e aemulatio.

\section{Do RECONHECIMENTO}

O Proaera é reconhecido pela Sociedade Brasileira de Estudos Clássicos (SBEC), pela Pró-Reitoria de Pós-Graduação e Pesquisa da UFRJ (PR2-UFRJ), pela Faculdade de Filosofia, Letras e Ciências Humanas da USP (FFLCH-USP), pelo Diretório de Grupos de Pesquisa do CNPq (DGP-CNPq), pelo Pólo de Estudos Clássicos do Rio de Janeiro (PECRJ), pelo Programa Interdisciplinar de Pós-Graduação em Linguística Aplicada da UFRJ (PIPGLA-UFRJ) e pelo Programa de Pós-Graduação em Filosofia da UFRJ (PPGF-UFRJ).

Integram o Proaera três ex-presidentes da SBEC (Professores Tatiana Ribeiro, Paulo Martins e Henrique Cairus, coordenador do Grupo), dois membros do Conselho Consultivo-Deliberativo (Professores Henrique Cairus e Ana Thereza Basílio Vieira) e dois ex-secretários gerais da mesma Sociedade (Professores Beatriz de Paoli e Fernando Santoro). Há um site no qual o Proaera disponibiliza informações e alguns textos que produz: http:// www.pec.ufrj.br/proaera ou http://www.letras.ufrj.br/proaera. 


\section{DA PRODUÇÃo}

No seio do Proaera foram produzidos várias Teses, Dissertações, artigos e traduções; esses textos estão todos disponíveis ou indicados no site do grupo. Cada produção do

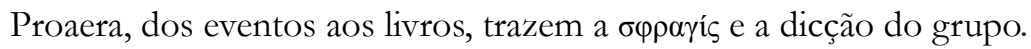

\section{Do INGRESSO E DO ESTATUTO}

Os integrantes ingressam no Proaera por anuência ao Convite feito por um de seus membros efetivos e endossado pelo conjunto dos participante, durante o Encontro Anual.

Desde janeiro de 2020, o Proaera possui um Estatuto (disponível no site www.pec. ufrj.br/proaera ou www.letras.ufrj.br/proaera), aprovado em sua Reunião Anual de 2019, que prevê seus objetivos, sua constituição, seu funcionamento e as formas de ingresso e de desligamento. 